\title{
SERIAL CARDIAC OUTPUT DETERMINATIONS IN MAN-
}

\author{
J. E. MerRiman, F.R.C.P.(c), G. M. Wyant, F.F.A.R.C.S., \\ G. BRAY, M.D., and W. MCGeACHY, M.D.
}

ThE ABILITY to measure cardiac output accurately under various conditions determined by anaesthetic agents and techniques and by surgical stress is of obvious interest. Even more important is the availability of a simple and reliable method of measuring serial cardiac outputs and thus of monitoring changes in cardiac dynamics. This information, when correlated to blood pressure readings, electrocardiograms, etc., will afford a much clearer picture of the reaction of the cardıovascular system to changing stress, than blood pressure, pulse, or electrocardiographic studies alone.

In order to be of clinical use, a method of serial cardiac output determination must be reasonably accurate, technically not too complicated, and not be overly time-consuming. It must require a minimum of expensive apparatus and technical personnel. Furthermore, such a method must not be harmful to the patient, must not increase the stress of surgery and anaesthesia significantly, and must leave no undesirable after-effects. To understand how these criteria may be fulfilled, it is best to consider briefly the various methods of cardiac output determination which have been developed in the past and to examine how they can be best adapted to serial determinations within these criteria.

There are three main groups of tests available, the physical methods, the gasometric methods, and the indicator-dilution methods.

\section{Physical Methods}

Analysis of the pulse wave contour has shown that the area under the aortic pressure curve is proportional to the stroke output and a factor related to the volume-elasticity characteristics of the vessel. It is possible to integrate these pressure curves electronically. If one were interested only in relative changes and not in absolute values, this method might have some merit for serial determinations. We have made only preliminary observations with this method.

The ballistocardiograph is actually a measure of cardiac force, but, because of the relationship between cardiac force and cardiac output, it has been used as a method for determination of cardiac output. Similarly, the pneumotachygram and the impedance cardiogram have not been found to be satisfactory by investigators in this field and none is in use at the present time as far as we are aware.

\section{Direct Fick}

\section{Gasometric Methods}

This method is generally accepted as the standard method for determination of cardiac output with which all newer methods must be compared. Determinations are made from the following formula:

$$
\text { Cardrac output }(\mathrm{L} . / \mathrm{min} .)=\frac{\mathrm{O}_{2} \text { consumption }(\mathrm{ml} . / \mathrm{min} .)}{\text { Pulmonary A-V } \mathrm{O}_{2} \text { difference }(\mathrm{ml} . / \mathrm{L} .)} .
$$

\footnotetext{
1From the Departments of Medicine and Anaesthesia, College of Medicine, University of Saskatchewan, and Cardio-Pulmonary Laboratory, University Hospital, Saskatoon, Saskatchewan.
} 
The difficulty of obtaining samples of mixed venous blood limits the use of this method The samples are obtained by means of cardiac catheterization with the catheter tip placed in the main pulmonary artery. Iit is at once obvious that a technique for cardiac output determination which requires cardiac catheterization cannot easily be adopted as a routine procedure. The cardiac catheter must be introduced under fluoroscopic and pressure control. Positioning of the catheter tip in other than the outflow tract of the right ventricle or in the main pulmonary artery is undesirable since the mixed venous blood is the major variable in the Fick determination. This is so because of the inadecuate mixing of coronary sinus blood in positions other than the ones mentioned.

For the greatest accuracy, all three samples in the equation must be collected over the same period of time, and therefore the final answer is a mean determination of cardiac output over the period of collection. This is usually the three minutes required for the collection of expired air.

It is apparent that the Direct Fick method, while accurate, is time-consuming. It does not lend itself readily to serial determinations under anaesthesia in man, because maintenance of the catheter tip in the same position is uncertain and because repeated air-sampling will interfere with maintenance of inhalation anaesthesia.

\section{Indirect Fick Procedures}

Krogh and Lindhard ( 1 ) first pointed out that measurements of cardiac output could be made from the rate at which a foreign gas of known concentration in the lungs is taken up by the blood. Several of the earlier reports of cardiac output determination were done by this method, using as the test gas either nitrous oxide or acetylene. This method has several obvious disadvantages for the determination of serial cardiac output, especially during anaesthesia.

Osborne et al. (2) have recently described a method which utilizes the lung as a tonometer. When rapid carbon dioxide analysers and different concentrations of carbon dioxide are used, it is possible to determine the mixed venous and arterial carbon dioxide tensions, as well as the total carbon dioxide production. This method does not requre the co-operation of the patient and can. be made over a period of 8 to 10 seconds.

\section{IndiCATOR-DILUTTON Methods}

The principle involved in all these methods is the same. An indicator in injected rapidly into the circulation and its subsequent concentration in the arterial blood is checked at frequent time intervals.

The indicator may be either a source of radioactivity or a foreign material, such as a dye. A scintillation counter is required to record the concentration of radioactive materials. The concentration of dyes in the arterial blood can be measured either by the collection of serial arterial samples, or by the withdrawal of arterial blood through a cuvette oximeter. The resulting dilution curves are then analysed and the cardiac output determined. 


\section{RaDioactive Isotopes}

Veall and associates in 1954 (3) and Huff and co-workers in 1955 (4) published methods of determining cardiac output in man by the in vivo analysis of radioactive iodinated human serum albumin (RIHSA). They were able to carry out a time-intensity analysis of $I^{131}$ with a highly shielded well-collimated scintillation detector placed over the chest. They advocated the use of 100-200 microcuries and went as high as 300 microcuries for repeated tests. The curves thus obtained, when analysed for cardiac output, gave values not significantly different from Direct Fick values obtained simultaneously. In seven patients and twenty-two dogs tested by the radioactive method and simultaneous Fick determinations, the means were not significantly different.

The technique for these tests is as follows. The detector is placed over the skin between the first and second ribs, immediately to the left of the sternum. This position is selected since here the outflow tract is closest to the anterior chest wall with a minimum of interposed tissues, since the blood flow through tissue would alter the radioactivity transient. The scintillation counter is connected to a countrate meter and a strip-chart recorder. We have found doses of 75 microcuries quite adequate to obtaln good curves and these need not be exceeded. As with all indicator-dilution methods, the indicator must be injected rapidly and immediately flushed with normal saline. The calculation of çardiac output from this curve is done by standard methods. Since the radioactive material is carried in plasma, knowledge of the plasma and blood volumes is essential. The total blood volume has been previously determined using $\mathrm{I}^{131}$ for plasma and $\mathrm{Cr}^{51}$ for red cell volumes.

The major disadvantage of this method for serial determinations is the relatively large dose of radioactıve material needed per injection. Although potassium ıdide is administered before and after the tests to block the thyroid, we believe that a total dosage of 300 microcuries should not be exceeded. Thus one is limited to approximately four determinations. A reduction in the amount of radioactive material injected would lead to a markedly flattened curve with greater errors in the results. This problem could be resolved by using a more sensitive detector of radioactivity.

The use of this method in the operatng room during anaesthesia presents still further disadvantages. First, the detector which we have been using is bulky. Secondly, for accurate determination of cardiac output it is necessary to know the exact blood volume of the patient at the time of each determination. This is simple in the experimental laboratory, but in the operating room, where blood loss and blood replacement are constantly proceeding, repeated determinations of blood volume will be necessary. This is relatively easy once plasma and red cells have been tagged initially, provided blood loss and replacement are known approximately. However, it would be advantageous to have a method of cardiac output determination which is independent of changes in blood volume.

In summary, then, this is a satisfactory method, but further technical advances, especially in the construction of scintillation counters are needed before it is an ideal method for serial cardiac output determinations, especially during operations. 


\section{Dye DLutton Methods}

\section{Evans Blue in Plasma}

A modified method for determining cardiac output by this means was described by Etsten and $\mathrm{Li}$ in 1954 (5). In brief, the method consists of the injection of a precise amount of T-1824 (Evans Blue) in $1 / 2$ per cent solution into the median basilic vein followed by a $10 \mathrm{ml}$. saline flush. Samples of arterial blood are collected, at the conclusion of the intravenous injection of dye, in 32 small glass tubes attached to a circular plastic disc. The disc is rotated by a motor in clockwise fashion at a speed of one tube per second. The arterial blood samples are centrifuged and the plasma transferred to individual microcuvettes. The dye concentration of each microcuvette is read on a Coleman spectrophotometer at a wave length of $625 \mathrm{~m} \mu$ against the plasma control in the first tube. The optical densities are translated into dye concentrations in milligrams per litre from a previously prepared plasma dye curve. These dye concentrations are plotted against time in seconds on sem1-logarithmic paper. The cardiac output is determinted from the dye concentration curve according to the method of Hamilton (6) and Eliasch (7):

$$
F=\frac{60 \times 1}{c t} \times \frac{100}{100-H}
$$

where $F=$ cardiac output in litres per minute

$I=$ amount of injected dye in milligrams

$c=$ mean concentration of dye in milligrams per litre

$t=$ passage time of dye in seconds

$H=$ haematocrit (not corrected for trapped plasma)

Etsten has shown that the values obtained by this method closely approximate those obtained with the Direct Fick method, if special attention is paid to a number of minor points mainly connected with the technique of injection of the dye. This method depends upon a free flow of arterial blood so that each tube contains an equal amount of blood. We have determined the time needed for each determination including centrifuging and pipetting off of plasma. In our laboratory it takes two technicians a total of $2 \frac{1}{2}$ hours to make one output determination. This time factor, then, is a real handicap for rapid serial determinations.

Evans Blue is slowly excreted from the body, and although it begins to leave the plasma within ten minutes of injection, it is held "or a long time in the reticuloendothelial system. Clinically this means that the satient will look increasingly blue and may continue to do so for several days o: even weeks with dye being slowly excreted; this may give rise to blue-stained urine. The total blood loss incurred from repeated determinations is not insignificant, since approximately $40 \mathrm{ml}$. of blood are withdrawn for each test. Lipaemia and haemolysis both interfere with dye determinations in the Etsten method.

For all these reasons the Etsten method for serial determination of cardiac output in man is impractical.

\section{Evans Blue in Whole Blood}

In order to obviate at least some of the disadvantages of the Etsten method, and to reduce the call on technicians' time, the method was modified in this 
laboratory by Rainbow and McGeachy. Since this has not been describec in the literature, it will not be discussed here in detail. Suffice it to say that two technicians workng together can complete the analysis of forty tubes in one hour. In normal subjects this method has been found satisfactory and, with normal arterial oxygen saturation, the effect of haemoglobin at $625 \mathrm{~m} \mu$ is minimal. Simultaneous determinations of cardiac output in volunteers with this and the original Etsten method show that the results are closely similar. They have been checked against the methods using radioactive isotopes and a gain results were comparable.

This modification shares with the Etsten method tre disadvantage that the subjects become increasingly blue. The method also has inherent difficulties arising from maintenance of tree arterial blood flow, and blood loss is by no means insignificant if a large number of determinations are done.

\section{Indicator Dilution Curves Using Cardio-Green}

The use of Cardio-Green obviates two of the great disadvantages of Evans Blue. (i) Since Cardio-Green does not accumulate in the body, repeated injections of the dye do not lead to discoloration of the patient. (ii) A monitoring cuvette system can be employed with a consequent saving in the time needed to analyse a series of individual samples and construct a dye-dilution curve from the results. Such a cuvette system gives unreliable results with Evans Blue since the system is sensitive to both dye concentration and changes in the percentage of oxygen saturation of the blood. Thus the curves are uninterpretable in the presence of fluctuations in oxtygen saturation. Cardio-Green does not have this disadvantage.

Fox and his co-workers have reported their studies with a tricarbocyanine dye which later has been given the trade name of Cardio Green (8). This dye has a peak concentration at a wave length of $800 \mathrm{~m} \mu$, a point at which the spectral transmission curves of oxyhaemoglobin and reduced haemoglobin intersect. This means that with this dye variations in oxygen saturation have no effect.

With the cuvette oximeter recording system in the determination of indicatordilution curves using Cardio-Green, only the infrared cell of the cuvette is used. This is sensitive at a wave length of $800 \mathrm{~m} \mu$.

Preliminary information reveals that Cardio-Green travels with the plasma proteins. Personal communication with several investigators has failed to reveal any instance of toxicity even in doses as high as $2 \mathrm{mg} . / \mathrm{kg}$.

In order to confirm that the dye is non-toxic, we have carried out a number of laboratory tests on eight volunteers on whom not less than six and as many as ten consecutive cardiac output determinations have been done. Tests included haemoglobin estimation, packed cell volume, and total and differential white blood counts. Liver function tests done were thymol flocculation, thymol turbidity, zinc sulphate flocculation, and blood albumin-globulin determinations, including electrophoresis for the various globulin fractions. A urinalysis including reaction, specific gravity, sugar, acetone, protein, and microscopic examination was also carried out. These tests were done both before and 48 hours after the cardiac output determinations. None of the tests showed any significant changes except in one subject who had had a pre-anaesthetic elevation of gamma globulin, 
thymol turbidity, and zinc sulphate turbidity; he showed a further rise of zinc sulphate turbidity on the day following the cardiac output determination. At the same time he also had a double plus thymol flocculation test. All these were repeated six days later and had by then returned to pre-experimental levels.

For the above reasons this method, using Cardio-Green as the indicator and the modified cuvette oximeter system as the recorder, was found to be the most suitable for our purposes for cardiac output determination.

Method. The volunteers were given a complete physical examination and those with significant diseases were excluded. Eight healthy subjects were chosen. They came to the laboratory in a fasting state. Candio Green was used in a concentration of $5 \mathrm{mg} . / \mathrm{ml}$. Figure 1 shows our injection apparatus.

The dye dilution curve was obtained as follows. Using an oiled $30 \mathrm{ml}$. syringe, blood was withdrawn at a steady rate from the artery through the cuvette oxi-

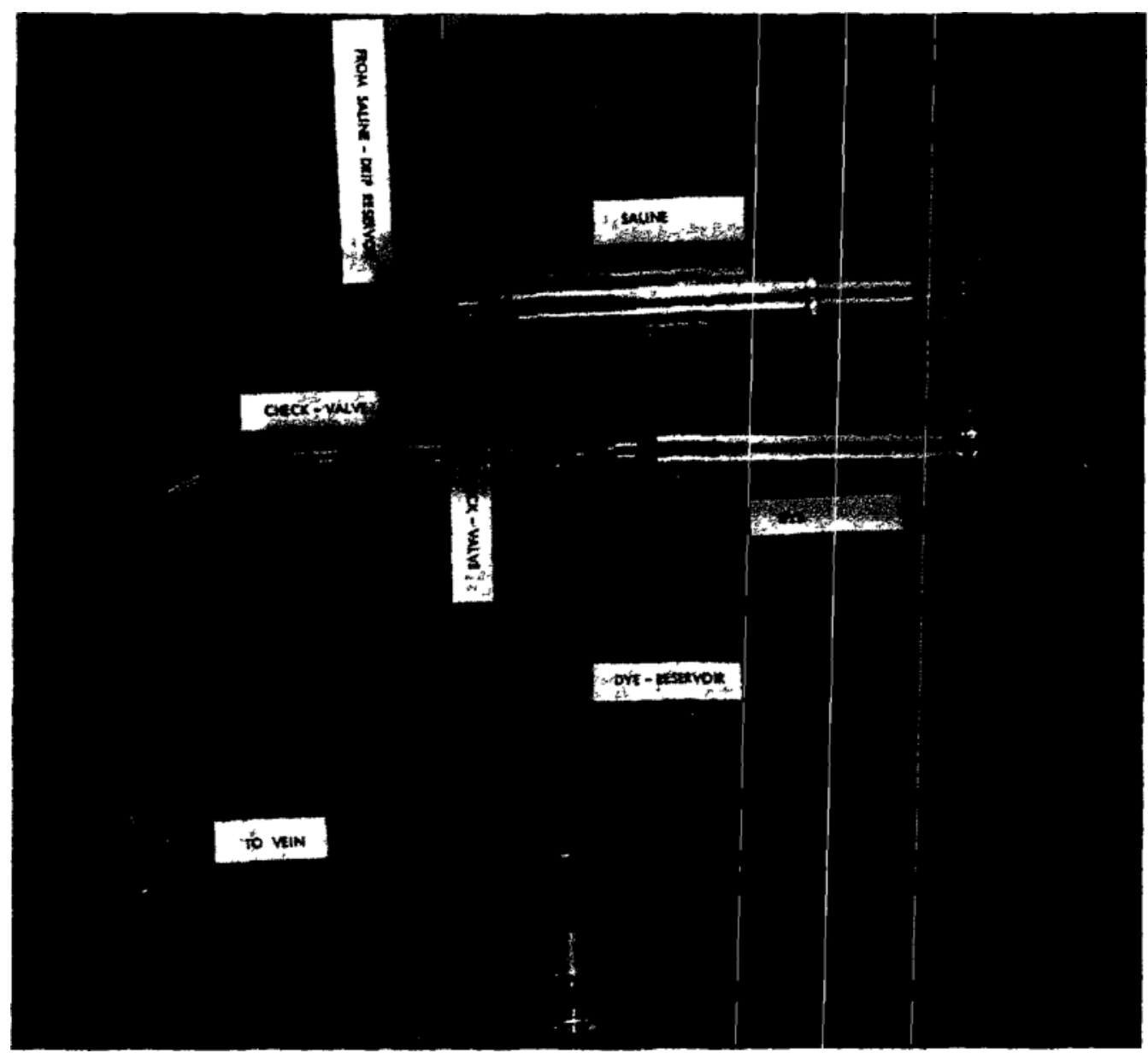

Figure 1. Injection apparatus for Cardio-Green The apparatus consists of two one-way check valves. One limb is connected by a three-way stop cock to two syringes containing Cardı-Green. One of these is used as a reservoir syringe; the other contains the measured dose of dye The other limb of the apparatus is connected by a three-way stopcock to a syrunge contalning saline and to an intravenous drip which acts as a saline reservoir. The whole unit is connected by a short segment of polyethy_ene tubing to the needle in the antecubital ven. 
meter. The light beam of the oximeter recorder was then put at zero and the signal for injection given. The measured dose of dye was injected quickly with one hand and a flushing dose of $10 \mathrm{ml}$. of saline was rapidly injected with the other hand. Injection and Alush were signaled on the oximeter recorder. The withdrawal of arterial blood through the cuvette was continued at a constant rate and each millilitre of withdrawal was recorded on the oximeter record.

Meanwhile, the light beam of the oximeter recorder was followed visually whlle being recorded on instantly developing photographic paper. When the plateau following the re-circulation hump was reached, the withdrawn blood was re-injected. Thus the net loss of blood to the patient was negligible. The equipment was then flushed with saline. The actual curve could be inspected within one minute of its completion. With practice an estimate of the cardiac output could be made immediately, but the actual curves were measured accurately later.

The Hamilton method (6) for calculation of cardiac output was used. Since the disappearance or clearing of the injected dye occurs exponentially, the descending limb of the curve was extrapolated on semi-logarithmic paper until a theoretical point of zero concentration was reached. This in actual practice was taken as $0.1 \mathrm{mg}$. $/ \mathrm{L}$. The area under this extrapolated curve was then determined, using a Keuffel and Esser planimeter, Model 4242. The area in square centimeters was then divided by the length of the base, giving a height which, when measured on the calibration curve, gave the mean concentration of dye in milligrams per litre. Cardiac output was then determined by the previously mentioned formula:

$$
F=\frac{60 \times I}{c t} .
$$

That part of the calculation which refers to haematocrit is omitted, since CardioGreen determinations are not influenced by changes in haematocrit.

Fıgure 2 shows some typical cardiac output curves in the same subject with both normal and reduced cardiac output, and using different amounts of dye.

This method of determining cardiac output has served us well, both in experimental work and in determinations on patients with various kinds of heart disease.

\section{Summary and ConcuUsions}

Of all the methods available for the serial determination of cardiac output, the one using Cardio-Green has proved the most suitable. Most other methods of cardiac output estimation do not lend themselves readily to many consecutive tests, with the exception perhaps of the ones using radioactive tracers. The suitability of the latter, however, depends upon the availability of highly sensitive counters so that the total dose of radioactive material injected during all these tests does not reach dangerous levels.

\section{RÉSUMÉ}

Nous avons étudié les diverses méthodes à notre disposition actuellement pour mesurer le débit cardiaque et nous avons discuté de l'utilité de chacune pour pratiquer des déterminations en série. 


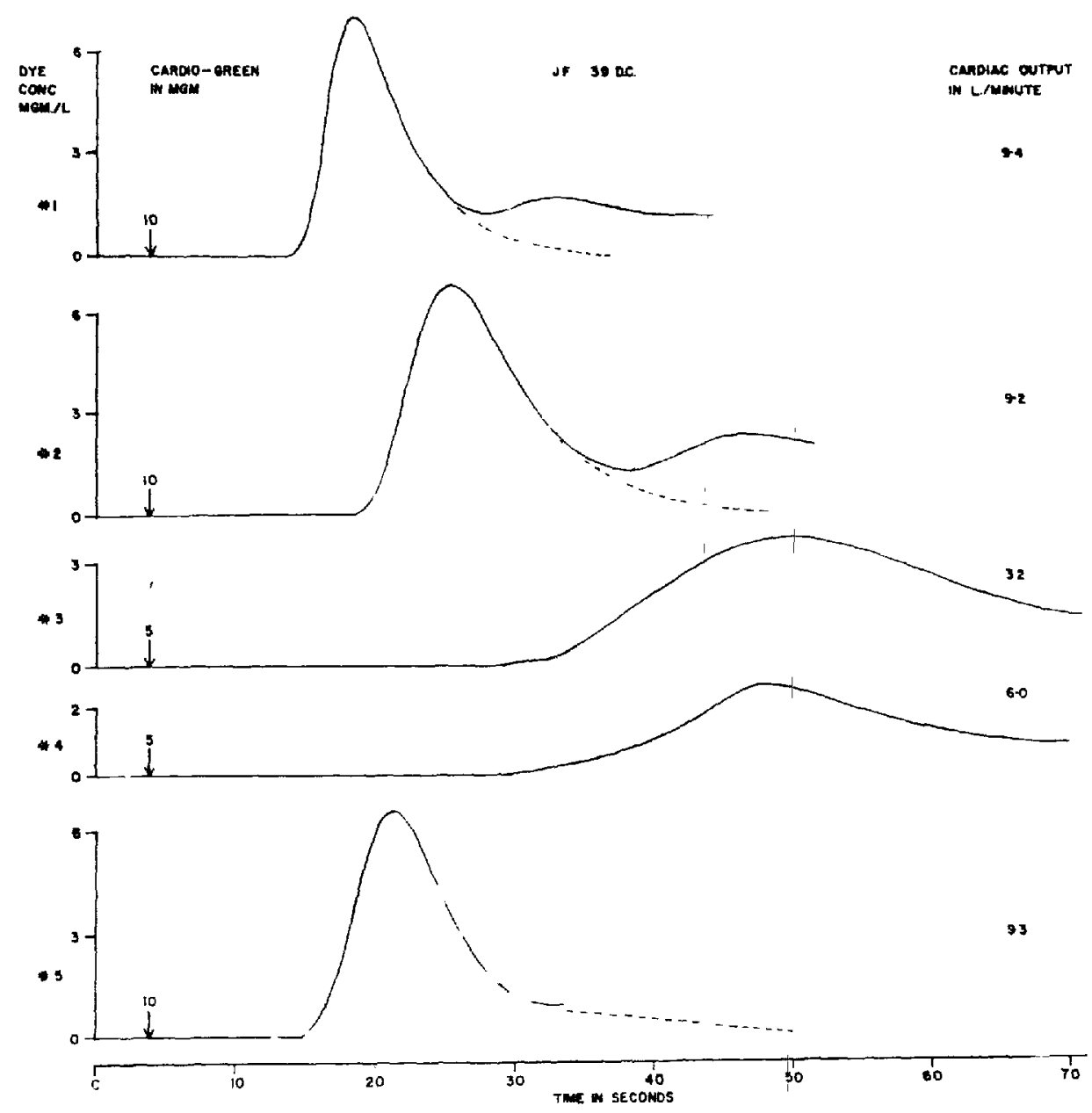

Figure 2. Typical curves of different cardiac outputs with different doses of dye.

On peut diviser en trois groupes les méthodes de mesurer le débit cardiaque: des méthodes physiques, gazométriques, et de dilution d'indicateur. Les diverses méthodes physiques comprennent l'analyse du tracé du pouls, la ballistocardiographie, la pneumotachygraphie, et l'impédance cardiographique. Les méthod'es gazométriques comprennent la détermination directe de Fick et un certain nombre de procédés indirects de Fick. En ce qui concerne les méthodes de dilution d'indicateur, on emploie soit des substances radioactives, soit des teintures. On a fait usage à maintes reprises du Bleu Evans pour déterminer des débits cardiaques, mais son emploi n'est pas pratique pour faire de nombreux tests consécutifs. Le Vert-Cardio, une teinture tricarbocyanine, possède plusieurs avantages sur le Bleu Evans dont les plus importants sont de ne pas s'accumuler dans l'organisme et de ne pas être toxique. On peut donc, en conséquence, chez le même individu, l'employer à répétition à de courts intervalles. On obtient les courbes de dilution rapidement à l'aide d'un système moniteur oxymètre cuvette, car la courbe définitive ne subit pas l'influence des variations de la saturation en oxygène du sang.

Nous avons décrit, en détail, la façon exacte d'employer le Vert-Cardio car elle est devenue notre méthode de choix pour déterminer le débit cardiáque 
chez l'humain. Le seule autre méthode convenable est celle de l'usage de matériel radioactif, à la condition d'avoir des compteurs très sensibles pour dépister la radioactivité de facon à ce que la radioactivité totale n'atteigne pas des proportions dangereuses.

\section{REFERENCES}

1. Krogh, A., \& Lindhard, J. Measurements of Blood Flow through Lungs in Man. Skandinav. Arch. f. Physiol. 27100 (1912).

2. Osborn, J. J. Rapid Measurement of the $\mathrm{pCO}_{2}$ of the Pulmonary Artefy in Man: Clinical Use in the Diagnosis of Congenital Heart Disease in 75 Patients. Proc. 30th Scientific Sessions, Am. Heart Ass. Circulation 16: 921 (Oct., 1957).

3. Veali, N.; Pearson, J D., Hanley, T., \& Lowe, A. E. A Method for the Determination of Cardiac Output: Preliminary Report. Proc. 2nd Radioisotope Conference, Oxford, July 19-23, 1954, pp. 183-192. London. Butterworth's Scientific Publications (1954)

4. Huff, R. L.; Feller, D. D, Judd, O. J , \& Bogardus, G. M. Cardiac Output of Men and Dogs Measured by in vivo Analysis of Iodinated (I131) Human Serum Albumin Curc. Res. 3(6). 564-569: (Nov., 1955).

5 Etsten, B. E. \& LI, T. H. The Determination of Cardiac Output by the Dye Dilution Method: Modifications, Comparison with the Fick Method, and Application during Anaesthesia. Anaesthesiology 15(3) 217-230 (May, 1954).

6 Hammton, W. F; Rruey, R. L., Artyah, A. M.; Cournind, A.; Foweld, D. M., Hrmmelstein, A; Nofle, R. P., Remington, J W ; Richaros, D. W., Jr., Wheelen, N. C.; \& Wrtha M, A. C. Comparison of Fick and Dye Injection Methods of Measuring Cardiac Output in Man. Am. J Physiol. 153(2): 309-321 (May, 1948).

7. Eliasch, H. Pulmonary Circulation at Rest and on Effort in Mitral Stenosis. Scandinav. J. Clin. \& Lab. Invest 4 (Suppl 4) (1952)

8. Fox, I. J., Brooker, L. G. S., Heseltine, D W.; Essex, H. E. \& Wood, E. H. A Tricarbocyanine Dye for Continuous Recording of Dilution Curves in Whole Blood Independent of Vanations in Blood Oxygen Saturation. Proc. Staff Meetings Mayo Clinic 32(18): 478-484 (Sept. 4, 1957). 